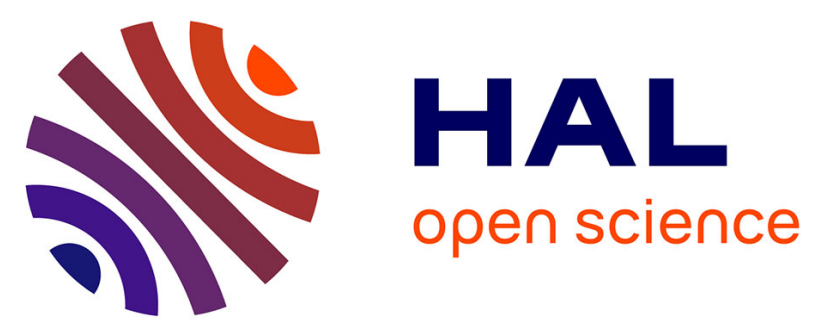

\title{
A SILICON PHOTODIODE ARRAY DETECTOR COVERING A LARGE SOLID ANGLE FOR FLUORESCENCE EXAFS MEASUREMENTS FROM 2 TO $25 \mathrm{keV}$
}

A. Retournard, M. Loos, I. Ascone, J. Goulon, M. Lemonnier, Robert Cortès

\section{To cite this version:}

A. Retournard, M. Loos, I. Ascone, J. Goulon, M. Lemonnier, et al.. A SILICON PHOTODIODE ARRAY DETECTOR COVERING A LARGE SOLID ANGLE FOR FLUORESCENCE EXAFS MEASUREMENTS FROM 2 TO 25 keV. Journal de Physique Colloques, 1986, 47 (C8), pp.C8-143C8-147. 10.1051/jphyscol:1986826 . jpa-00226147

\section{HAL Id: jpa-00226147 https://hal.science/jpa-00226147}

Submitted on 1 Jan 1986

HAL is a multi-disciplinary open access archive for the deposit and dissemination of scientific research documents, whether they are published or not. The documents may come from teaching and research institutions in France or abroad, or from public or private research centers.
L'archive ouverte pluridisciplinaire HAL, est destinée au dépôt et à la diffusion de documents scientifiques de niveau recherche, publiés ou non, émanant des établissements d'enseignement et de recherche français ou étrangers, des laboratoires publics ou privés. 


\title{
A SILICON PHOTODIODE ARRAY DETECTOR COVERING A LARGE SOLID ANGLE FOR FLUORESCENCE EXAFS MEASUREMENTS FROM 2 TO $25 \mathrm{keV}$
}

\author{
A. RETOURNARD*, M. LOOS* I. ASCONE* **, J. GOULON*** , \\ M. LEMONNIER** and R. CORTES ${ }^{* * *}$ \\ *Laboratoire de Chimie Théorique, Université de Nancy I, \\ U.A. 510 CNRS, B.P. 239, F-54506 Vandoeuvre-1es-Nancy Cedex, \\ France \\ **LURE, L.P. CNRS, MEN, CEA, université de Paris-Sud, \\ Bâtiment 209D, F-91405 orsay Cedex, France \\ *** Laboratoire de Physique des Liquides et Electrochimie, \\ G.R. 4 CNRS, Université Pierre et Marie Curie, (Paris IV), \\ 4 Place Jussieu, F-75230 Paris 05, France
}

\begin{abstract}
RESUME
On montre qu'un rếseau de quatre photodiodes en silicium utilisées en mode photovoltaïque présente de réels avantages sur les autres types de détecteurs de fluorescence: grande efficacité, réponse parfaitement linéaire, compatibilitê avec les techniques de vide pour les utilisations dans le domaine des RX mous, absence d'alimentation en tension et de gaz. Les diodes doivent être refroidies jusqu'à $几-120^{\circ} \mathrm{C}$ afin de réduire leur courant d'obscuritê et le bruit thermique de la résistance équivalente de shunt. On présente des spectres typiques d'une solution diluée de cytochrome $c$ et d'un liquide extrêmement absorbant dans le domaine des rayons $X$ mous : $\mathrm{C}_{2} \mathrm{Cl}_{4}{ }^{*}$.

ABSTRACT

A $\mathbf{S i}$-photodiode array detector operated in the photovoltaic mode is shown to offer several advantages over other fluorescence detectors: high efficiency, perfect linearity of the response, vacuum compatibility for soft X-ray measurements, absence of gas and voltage supplies. Low temperature cooling down to $-120^{\circ} \mathrm{C}$ is needed in order to decrease the dark current and thermal noise of the shunt resistance. Typical spectra recorded on a dilute cytochrome $c$ solution and on a liquid which is strongly absorbing in the soft $\mathrm{X}$-ray range i.e. $\mathrm{C}_{2} \mathrm{Cl}_{4} \mathrm{t}$ are presented.
\end{abstract}

\section{INTRODUCTION}

The advantages of the fluorescence detection of EXAFS/XANES spectra are well recognized for dilute and thin samples since the pioneering experiments reported by JAKLEVIC et al. (1). Over recent years, it was also realized that fluorescence detection can be helpful in cases of concentrated but strongly absorbing samples (2), especially in the soft $X$-ray range (3) or when sample inhomogeneities can produce more or less severe distortions of the conventional absorption spectra (4). For these diverse applications one needs low cost detectors featuring a high sensitivity, very low noise level, no counting rate limitation and perfect linearity. In addition, one wishes to collect the fluorescence photons over as large a solid angle as possible. Energy discrimination between fluorescence and elastic/inelastic signals, or between fluorescence emissions of various elements would obviously be desirable : energy dispersive detectors can, in principle, afford the required energy resolution but only at low counting rates and if the relative intensities of the signals to be resolved are comparable. Unfortunately, these conditions can only be satisfied by using an expensive array of independent energy dispersive detectors each one having its own adapted prefilter made of an absorbing microfoil of a selected element (5). 
II. BASIC OPTIONS

Advantages or limitations of the most usual detectors can be summarized as follows :

1) Scintillation counters : NaI(T1) crystal scintillators of various size and shape $(\overline{7,8})$ or plastic scintillators have reasonable efficiency and are coupled to high gain photomultipliers. These detectors offer the best compatibility with high speed data processing but their energy resolution is very poor as the energy $\varepsilon_{e^{-}}$ required to create one photoelectron is $\approx 300 \mathrm{eV}$. However, this limitation is not very dramatic here. Of more concern to us is the compromised linearity beyond c.a. $10^{5} \mathrm{c} / \mathrm{s}$ whereas operation below c.a. $4 \mathrm{keV}$ is usually not possible.

2) Gas detectors : benefit from a much lower $\varepsilon_{e^{-}}$value $(\sim 30 \mathrm{eV})$.

- Gas filled ion chambers are easily contructed devices (3) but their sensitivity is limited by electronics and often suffers from artefactual microphonic or pressure fluctuation effects. Large area, vacuum tight windows are also difficult to realize for soft $\mathrm{X}$-ray operation.

- Proportional counters have a larger gain but still a much lower efficiency than scintillators. Energy resolution, especially for gas scintillation proportional counters is improved... but only at low counting rates. Performances are strongly dependent on the purity and stability of gas mixtures and pressure fluctuations.

3) Semiconductor devices : $\mathrm{Si}, \mathrm{Ge}, \mathrm{AsGa}, \mathrm{CdTe}, \mathrm{HgI}_{2} \ldots$ show the lowest $\varepsilon_{\mathrm{e}^{-}}$values $(\leqslant 4 \mathrm{eV})$, have a small Fano factor and therefore can always reach superior energy resolving performances and a better noise rejection. These devices have no internal gain except for avalanche diodes which are now also being considered for use. Therefore ultra-low noise electronic amplification of the output signal is needed. Two modes of operation can be considered :

- In the photovoltaic mode large size photodiodes or photodiode arrays can be used. High detection efficiency is obtained without any reverse bias voltage and the short circuit photocurrents are linear with photon intensities over 8 decades or more before the junction begins to saturate (8). Vacuum compatibility for soft $x$-ray measurements, absence of gas and voltage supplies are obvious advantages $(8,9)$.

- In the energy dispersive mode a reverse bias voltage is applied. Best energy resolutions are obtained with ultra-pure $\mathrm{Ge}$ or $\mathrm{Si}$ diodes of small size (area $\leqslant 100$ $\mathrm{mm}^{2}$ ) operating at low temperature as these diodes then exhibit the best charge collection properties (mobility of charge carriers $x$ carrier lifetime) (10). Room temperature operation is even possible for Si, $\mathrm{AsGa}$, CdTe and $\mathrm{HgI}_{2}$ but with rather poor energy resolutions except for $\mathrm{HgI}_{2}$ in the soft $\mathrm{X}$-ray range $(10,11,12)$.

As far as fluorescence detection of EXAFS/XANES spectra is concerned, energy resolution was not retained as a first priority requirement :

- Elastic/inelastic scattering contributions can be selectively absorbed in metal filters of appropriate nature and thickness, or taking advantage of the polarized nature of synchrotron radiation (5). In the case of fluorescent matrices, a double fluorescence detection scheme has also been proposed for eliminating the noise generating fluorescence of the matrices (13).

- An efficient two mirror harmonic rejector is inserted behind the monochromator of the EXAFS-II station when operating in the soft X-ray range or at energies below $9 \mathrm{keV}$ in order to suppress all harmonics.

On the other hand, a new method for manufacturing large area (52 $52 \mathrm{~mm}^{2}$ ) silicon photodiodes featuring ultra-low reverse currents and dark currents has been developed by ENERTEC-SCHLUMBERGER (FRANCE) following the so-called planar process first introduced by KEMMER (14). This process which combines oxide passivation, photo-engraving and ion implantation resulted in improved charge carrier lifetime while the surface leakage currents were eliminated (15). This technological advance prompted us to try and use these diodes in the photovoltaic mode for the fluorescence detection of EXAFS/XANES spectra.

III. DETECTOR DESIGN AND PERFORMANCES

Two prototypes were successively built which differ only by the number and configuration of photodiodes and by their cooling system. Schematics of the improved version (II) and of its associated electronics are reproduced in figures $1 \mathrm{~A}, 1 \mathrm{~B}$, IC. 
(i) Low temperature operation is needed in order to decrease the dark current : a continuous flow of cooled (helium) gas gives a long term temperature stability of $\pm 1^{\circ} \mathrm{C}$ with typically $-120^{\circ} \mathrm{C}<\mathrm{T}<-100^{\circ} \mathrm{C}$, the diodes being set in a vacuum chamber under permanent pumping ( $\mathrm{P} \sim 10^{-2}$ torr).

(ii) The samples are placed in an internal chamber machined from "permaglas" and are isolated from the external detector chamber by a thin $(3 \mu \mathrm{m})$ polyester window which is vacuum tight on both sides. Sample holders were machined from magnesium and graphite and can be cooled down to liquid $\mathrm{N}_{2}$ as the sample chamber can also be vacuum pumped independently from the detector chamber. The sample holder can fit as well vacuum tight liquid cells machined from a chemically inert plastic material (DELRIN trademark from DUPONT DE NEMOURS).

(iii) In order to improve the linearity of the whole measurement chain, the intensity of the incident beam is now measured with the same kind of diode cooled down to the same temperature : this diode detects the scattered radiations from an aluminized mylar film or of some selected metal microfoil.

(IVi) Fluorescence photons should be collected over a large solid angle but a compromise had to be found between increasing the signal and increasing the dark current proportional to the detector area. A reasonable compromise was found with four diodes collecting the signal over more than $15 \%$ of $4 \pi$.

(Vi) The preamplifier stages are kept as close as possible to the photodiodes whereas the amplification gain can be selected from outside the experimental hutch.
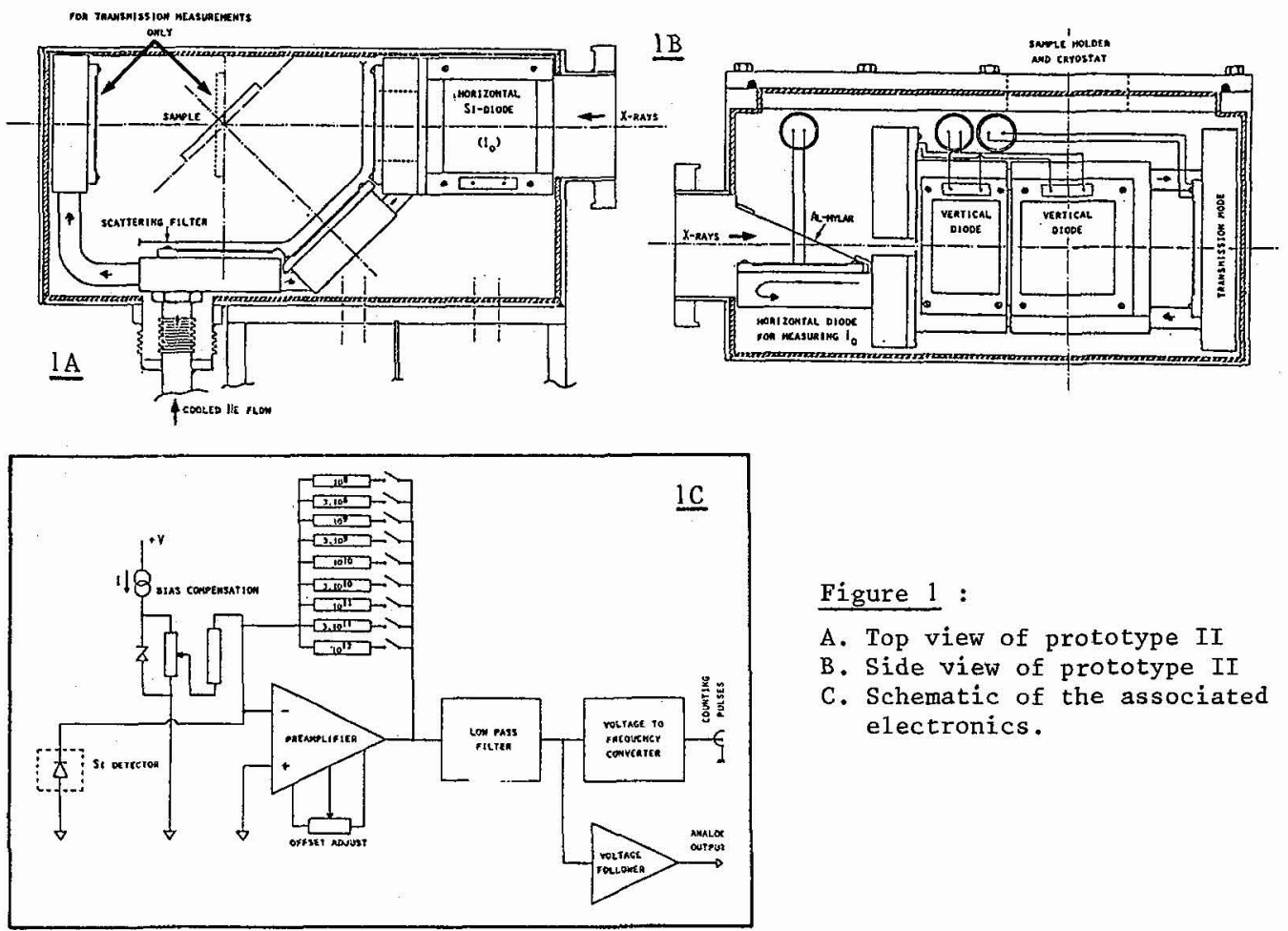

Figure 1 :

A. Top view of prototype II

B. Side view of prototype II

C. Schematic of the associated electronics.

As regards noise currents, it is noteworthy that the noise contribution of our "home made" amplification chain, which was found to be of the order of $4.810^{-15} \mathrm{~A}$ in a $10 \mathrm{~Hz}$ bandpass, is not yet the limiting contribution as compared to the residual dark current and to the thermal noise current due to the shunt resistance $R_{s h}$ of the diode. For a single diode $\left(52 \times 52 \mathrm{~mm}^{2}\right.$ area), the dark current $I_{d}$ measured at 
$25^{\circ} \mathrm{C}$ was c.a. $2 \mathrm{nA}$ but dropged rapidly with temperature according to the empirical law $I_{d}(T)=I_{d}\left(T_{o}\right) 2(T-T o) / \delta$ where $\delta 1$ ies between $6^{\circ} \mathrm{C}$ and $10^{\circ} \mathrm{C}$. Assuming $\delta \sim 8^{\circ} \mathrm{C}$, one obtains $I_{d}\left(-120^{\circ} \mathrm{C}\right)=7 \cdot 10^{-15}$ A for a single diode. It is not possible to make an accurate measurement of $R_{\mathrm{Sh}}$ but taking as a reasonable estimation $\mathrm{R}_{\mathrm{Sh}}\left(-120^{\circ} \mathrm{C}\right) \sim 10^{8} \Omega$, the calculated thermal noise would be, again for a single diode, of the order of 3. $10^{-14} \mathrm{~A} / 10 \mathrm{~Hz}$ bandpass. As the experimentally measured noise leve1, for the four diode prototype II, is of the order of $10^{-13} \mathrm{~A} / 10 \mathrm{~Hz}$ bandpass, it seems that the value of $R_{S h}$ was only slightly underestimated. Nevertheless the performances of the detector appear clearly limited by the characteristics of the diodes even at low temperatures.

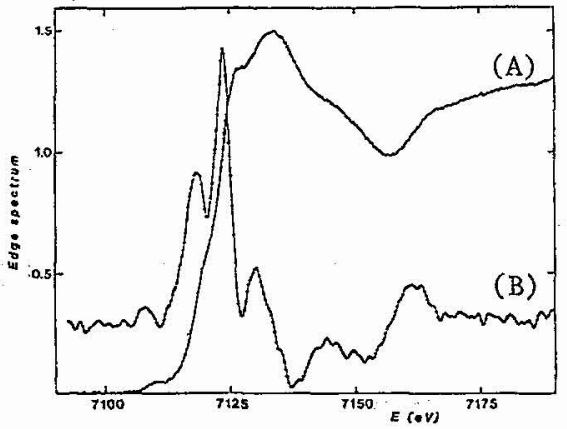

Figure 2 : Fe K-edge XANES spectrum (A) and its first derivative spectrum (B) of a 0.003 M solution of oxidized cytochrome c. Two scans were added. Data acquisition time: 3 s per data point.

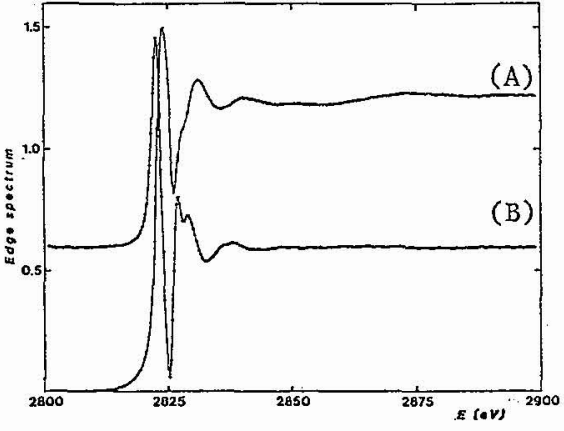

Figure 3 : $\mathrm{C} 1 \mathrm{~K}$-edge spectrum (A) and its first derivative spectrum (B) of pure $\mathrm{C}_{2} \mathrm{Cl}_{4}$ (single scan $-2 \mathrm{~s}$ per data point).

Typical spectra recorded with this detector are reproduced in figures 2 and 3 . As illustrated by figure 2 , good data could be obtained in only few scans for a $0.003 \mathrm{M}$ solution of oxidized cytochrome $\mathrm{c}$. As compared to earlier spectra also recorded in the fluorescence mode but with a gas filled ion chamber, the new data are improved by a factor $\simeq 15$ in signal/noise ratio. The detector was also used quite sucessfully in the soft $\mathrm{X}$-ray range : a single scan XANES spectrum at the chlorine $\mathrm{K}$-edge is shown in figure 3 for pure liquid $\mathrm{C}_{2} \mathrm{Cl}_{4}$ which is too absorbing to be investigated in the conventional absorption mode.

\section{CONCLUSION}

The present detector offers several advantages over gas filled ion chambers used for fluorescence measurements : a superior efficiency, vacuum compatibility for soft $\mathrm{X}$-ray experiments, absence of gas and voltage supplies but it suffers from all complications inherent to low temperature operation. As compared to scintillators, it is not counting rate limited, its linearity is quite remarkable and finally it can be used without any difficulty in the soft $X$-ray range.

\section{ACKNOWLEDGEMENTS}

Acknowledgements are due to L. LECLERC and C. MARCHAL for their technical assistance in the mechanical realization of the detector. We are also grateful to Drs. R. HENCK and M.O. LAMPERT (ENERTEC-Strasbourg) for their interest in our project.

\section{REFERENCES}

(1) J. JAKLEVIC, J. KIRBY, M.P. KLEIN, A.S. ROBERTSON, G.S. BROWN and P. EISENBERGER, Solid State Commun. 23, 679 (1977).

(2) K. NAMIKAWA and S. HOSOYA, Jap. J. App1. Phys. 21, L687 (1982).

(3) F.W. LYTTLE, R.B. GREEGOR, D.R. SANDSTROM, E.C. MARQUES, J.WONG, L.C. SPIRO, G.P. HUFFMAN and F.E. HUGGINS, NucI. Instrum. Methods 226, 542 (1984).

(4) J. GOULON, C. GOULON-GINET, R. CORTES and J.M. DUBOIS, J. Physique 43,539 (1982).

(5) E.A. STERN and S. HEALD, Rev. Sci. Instrum. 50, 1579 (1979). 
(6) S.P. CRAMER and R.A. SCOTT, Rev. Sci. Instrum. 52, 395 (1981).

(7) S.S. HASNAIN, P.D. QUINN, G.P. DIAKUN, E.M. WARDELL and C.D. GARNER, J. Phys.E $17,40(1984)$.

(8) T. JACH and P.L. COWAN, Nucl. Instrum. Methods 208, 423 (1984).

(9) Y. TAKEUCHI, H. HOSOMATSU, M. WADA, J. SUZUKI and T. YAMAZAKI, Photon Factory Activity Report VI-138 (1983).

(10) G.A. ARMANTROUT, Nuc1. Instrum. Methods 193, 41 (1982).

(11) M. YABE, N. SATO, H. KAMIJO, T. TAKESHI and F. SHIRAISHI, Nuc1. Instrum. Methods $193,63(1982)$.

(12) J.S. IWANCZYK, J.H. KUSMISS, A.J. DABROWSKI, J.B. BARTON, G.C. HUTH, T.E. ECONOMOU and A.L. TURKEVICH, Nuc1. Instrum. Meithods 193, 73 (1982).

(13) J. WONG and K.J. RAO, Solid State Commun. 45, 853 (1983).

(14) J. KEMMER, Nuc1. Instrum. Methods 169, 499 (1980).

(15) J. KEMMER, P. BURGER, R.HENCK and E. HEIJNE, IEEE Trans.Nuc1.Sci.29, 733 (1982). 